\title{
Breves reseñas biográficas
}

\section{Joaquim Rius-Ulldemolins}

Joaquim Rius-Ulldemolins es Doctor en Sociología por la Universidad Autónoma de Barcelona y la École des Hautes Études en Sciences Sociales. Actualmente, es Profesor Ayudante Doctor en el Departamento de Sociología y Antropología Social de la Universidad de Valencia. Es miembro del grupo de Investigación Nebrija Grupo de Arte. Es autor de varios libros y artículos sobre la sociología de la cultura y la política cultural en revistas nacionales e internacionales. Sus intereses de investigación se centran en el análisis de los clústeres y las profesiones creativas, en el rol de las instituciones culturales en la política cultural o en la instrumentalización de la cultura en el branding urbano y territorial.

\section{Arturo Rubio Arostegui}

Arturo Rubio Arostegui es Doctor en Ciencias Políticas y Sociología (Universidad Complutense de Madrid), Master en Gestión de las Artes (música, teatro y danza), Licenciado en Filosofía y Ciencias de la Educación. Actualmente, es profesor de la Universidad Antonio de Nebrija e Investigador Principal de Investigación Nebrija Grupo de Arte y miembro del Grupo de Investigación de la Universidad de Barcelona CECUPS . Sus campos de investigación y docencia son: política cultural, gestión cultural, sociología del arte, educación Artística, metodología de la investigación en las artes. Ha participado en Proyectos Nacionales de I + D + i y ha publicado libros y artículos en revistas indexadas (JCR) en estos campos del conocimiento. Ha recibido el Premio Nacional de Investigación (Ministerio de Administraciones Públicas., 2002).

\section{Gil-Manuel Hernàndez i Martí}

Historiador y Sociólogo, Doctor en Geografía e Historia, Profesor Titular del Departamento de Sociología y Antropologia Social de la Universidad de Valencia. Es autor de diversos libros, artículos e investigaciones sobre las manifestaciones festivas y rituales de la cultura popular, el patrimonio cultural y los procesos de globalización. También se ha ocupado del estudio de políticas culturales, identidades colectivas y nuevas formas de espiritualidad. Entre sus últimos libros están "Sociologia de la globalització. Anàlisi social d'un món en crisi” (2013) y “Ante el derrumbe. La crisis y nosotros” (2015). 


\section{Francisco Torres Pérez}

Doctor en Sociología por la Universidad de Valencia. Ha sido profesor en la Universidad de Murcia y actualmente lo es en la de Valencia, en su Departamento de Sociología y Antropología Social. Sus campos de investigación son la sociología de las migraciones y la sociología urbana con diversas líneas como la inserción vecinal y laboral de los inmigrantes, en ámbitos rurales y urbanos, sociabilidad y relaciones inter-étnicas, políticas públicas de inmigración y urbanismo neoliberal y desigualdad urbana. En los últimos años se ha centrado en los impactos de la crisis en estos ámbitos. Ha publicado varios volúmenes, artículos y numerosos capítulos. Entre sus últimas publicaciones, "Crisis y estrategias de los inmigrantes en España: el acento latino", Revista CIDOB d'Afers Internacionals 106-107 (2014) y el volumen colectivo Crisis, inmigración y sociedad (2015), Ed. Talasa, Madrid (coeditado con E. Gadea).

\section{Juan Pecourt Gracia}

Juan Pecourt es licenciado en Humanidades y Estudios Culturales por la Nottingham Trent University, doctor en Ciencias Políticas y Sociología por la Universidad de Cambridge y profesor de Sociología en la Universidad de Valencia. Desde 2005 es Life Member del Clare Hall College de Cambridge.

\section{María Victoria Sánchez Belando}

María Victoria Sánchez Belando es candidata a Doctora en Sociología y profesora asociada del Departamento de Teoría Sociológica de la Universidad de Barcelona. Desde 2012 forma parte del Centro de Estudios sobre Cultura Política y Sociedad de la Universidad de Barcelona desde donde ha participado en diferentes investigaciones sobre sociología de la cultura y políticas culturales. Sus intereses investigadores se centran en la innovación y la participación social en el ámbito de la cultura y en la relación entre cultura, creatividad y políticas urbanas.

Entre sus publicaciones más recientes destacan, en 2015, "Modelo Barcelona y política cultural: usos y abusos de la cultura por parte de un modelo emprendedor de desarrollo local en EURE, Revista Latinoamericana de Estudios Urbano Regionales, Santiago de Chile (con Joaquim Rius Ulldemolins) y en 2012, ¿Ciudad creativa y ciudad sostenible?: Un análisis crítico del modelo Barcelona de políticas culturales, publicado en la Revista Crítica de Ciências Sociais de la Universidad de Coimbra, Portugal (con Joaquim Rius Ulldemolins y Matias I. Zarlenga).

\section{Alex Tusell Collado}

Licenciado en Ciencias Políticas y de la Administración por la Universitad Autónoma de Barcelona y Máster en Análisis Político por la Universidad Abierta de Cataluña. 


\section{Luca Sebastiani}

Luca Sebastiani es doctor en Antropología Social y Diversidad Cultural por la Universidad de Granada (2014) y licenciado en Ciencias Políticas por la Universidad de Bolonia (2006). Actualmente es miembro del Laboratorio de Estudios Interculturales y del Instituto de Migraciones de la Universidad de Granada. Sus principales intereses de investigación son las migraciones transnacionales y la globalización, las políticas de inmigración e integración, los procesos participativos y los movimientos sociales y ciudadanos.

\section{Xavier Mínguez Alcaide}

Xavier Mínguez Alcaide es doctor en psicología por la Universidad del País Vasco/ Euskal Herriko Unibertsitatea. Ha desarrollado su trabajo entorno a la paz y los derechos humanos en el País Vasco y Colombia. Como miembro del grupo de investigación en cuestiones sociales Gune Irekiak, actualmente es el responsable de un estudio para favorecer la reconstrucción del tejido social en el País Vasco, en el marco de Donostia 2016 Capital Europea de la Cultura.

FINANCIACIÓN DEL ESTUDIO: El presente estudio ha sido financiado por la Diputación Foral de Gipuzkoa, a través del grupo de investigación Gune Irekiak.

\section{Eguzki Urteaga}

Eguzki Urteaga es Profesor de Sociología en la Universidad del País Vasco (UPV) e Investigador asociado en el Social and Business Research Laboratory (SBRlab), centro de investigación de la Universidad Rovira i Virgili. Este Doctor y Licenciado en Sociología por la Universidad Victor Segalen Burdeos 2 y Licenciado en Historia especialidad Geografía por la Universidad de Pau y de los Países del Adour, es autor de 29 libros entre los cuales figuran: La politique linguistique en Pays Basque (2004), La nouvelle gouvernance en Pays Basque (2004), La coopération transfrontalière en Pays Basque (2007) o Perceptions sociales de la science et de la technologie en Pays Basque (2010) así como de más de 150 artículos universitarios tanto en Europa, en América latina como en Canadá. Es igualmente Director de Colección en la editorial de París Mare et Martin y ha sido profesor invitado en varias Universidades europeas (Burdeos, Lovaina, Coímbra, París).

\section{Eduardo Alvarado Espina}

Doctorando en el programa de Ciencias Políticas en la Universidad Complutense de Madrid. Máster en Diplomacia y Relaciones Internacionales, con especialidad en Cooperación al Desarrollo. Máster en Análisis Político. Licenciado en Ciencias Políticas y Administrativas. Cofundador, redactor y subdirector de la Revista Digital Política Crítica, 
publicación dedicada al análisis político internacional, primordialmente euroasiático y latinoamericano. Líneas de investigación: política comparada, teoría democrática, teoría del poder político, geopolítica e historia política.

\section{Rosa María Frasquet Aira}

Licenciada en Periodismo por la Universidad Autónoma de Barcelona. Licenciada y Máster en Antropología Social y Cultural por la Universidad de Barcelona, con la tesina "De la soledad a la autonomía. Procesos de construcción identitaria y legitimación de la maternidad como un proyecto individual". Miembro del Grup de Recerca en Antropologia del Parentiu i el Patrimoni (GRAPP-UB). Está desarrollando su tesis doctoral, que profundiza en el análisis de la maternidad en solitario por elección y las transformaciones de la maternidad en la sociedad contemporánea, desde una perspectiva de género. 